\title{
Peritoneal Necrotic Lesion
}

National Cancer Institute

\section{Source}

National Cancer Institute. Peritoneal Necrotic Lesion. NCI Thesaurus. Code C78543.

A necrotic process affecting the peritoneum. 